\title{
Feitio de Viver, de Gizêlda Melo do Nascimento
}

\author{
Virgínia Maria Gonçalves \\ Universidade Estadual de Londrina
}

eitio de viver - memórias de descendentes de escravos ( Londrina, Editora da Universidade Estadual de Londrina, 2006), é título de um livro de Gizêlda Melo do Nascimento, resultante de uma tese de doutorado, defendida em 1995, na Escola de Comunicação da Faculdade Federal do Rio de Janeiro. O título do livro evoca também um feitio da escritura, saborosamente entretecida com os fios das memórias de descendentes de escravos do Rio de Janeiro. Incorporando o espírito da "nova história" dos Annales franceses, tal como foi formulada por Lucien Febvre, Marc Bloch e, mais tarde, por Fernand Braudel, a sua autora privilegia os inquéritos coletivos na vida contemporânea, reveladores de revelar um tempo descontínuo, ou da "longa duração", no contraponto com a linearidade e a objetividade de uma "história dos acontecimentos", de extração positivista, obcecada com a noção de progresso e de tempo histórico objetivo e global. Mas, Feitio de Viver não é um livro para provar a validade dos ensinamentos revolucionários da escola dos Annales, a ponto de fazer exaustivas incursões teóricas para demonstrar erudição fácil. Feita a breve Introdução, que principia por algumas indagações inquietantes sobre nossa identidade cultural, segue-se, no primeiro capítulo, intitulado "Da Redenção de Cam, uma primorosa análise e interpretação de um quadro encontrado ao acaso, Redenção de Cam, de Modesto Brocos y Gómes, de 1895, no Museu Nacional de Artes do Rio de Janeiro. A partir da tela, o olhar atento vai compondo uma síntese da sociedade brasileira, tocando nas feridas que se escondem sob o rótulo do progresso e da civilização, quando a Casa Grande lança sombras cada vez mais densas sobre a senzala, numa sociedade, de modo que a redenção anunciada se confunde com um projeto ideológico de progressivo embranquecimento da sua população, para superar a suposta inferioridade racial e cultural do negro. 
Fica evidente que o livro não se produziu para ajustar-se, rigorosamente, a conceitos pré-formulados de história, incluindo aquela que realizou uma revolução epistemológica quanto ao conceito de tempo histórico e que se disseminou no século XX sob o rótulo de "nova história". Entretanto, é inegável que esta acaba por refletir-se em Feitio de viver, pelo destaque conferido à oralidade, como uma das formas de iluminar o campo econômico e social, desvelando o modo como as pessoas produzem, consomem, mantêm suas crenças, organizam-se socialmente, preservam laços familiares, e como resistem num meio hostil, especialmente na condição de negros, mulheres, pobres, vivendo na periferia do Rio de Janeiro, como é o caso em questão. A forma adotada pela autora não comporta a aridez da maioria dos trabalhos acadêmicos, recheados de citações consagradas e de coleta impessoal de informações, apresentandose, antes, como um discurso literário impregnado de força poética, sensível à oralidade, capaz de revelar um mundo em transformação no qual pulsa o dia-a-dia de narradores anônimos, na sua maioria constituídos por mulheres afro-descendentes, que, segundo a autora, vivem na " condição de escravos, alforriados ou fugidos, enfim, todo um chão classificador repousado em terminologias que os distinguem como pertencentes a um grupo de homens destituídos de direitos e garantias indispensáveis à vida”.

É possível constatar, na referida obra, a empatia da autora com as entrevistadas, deixando à mostra uma adesão ideológica e uma aproximação afetiva que até poderia colocar em risco a objetividade das análises, se ela não se armasse de precauções para se posicionar com certa distância crítica do seu objeto, sem abafar a indisfarçável identificação de origem e de gênero que mantém com ele. Enfim, prevalece o equilíbrio, fica garantida a seriedade da pesquisa que não se prende aos "grandes acontecimentos", navegando sempre entre o presente e o passado, com o intercurso da oralidade. Mas, antes de tornarse olhos e ouvidos para seus depoentes, a autora faz uma leitura da tela de Modesto Brocos y Gómes, como se disse antes, mostrando sua competência para a análise e interpretação de outros textos não verbais, como documentos fundamentais de uma outra época, revelando uma perspectiva sobre o nosso processo de mestiçagem segundo a concepção eugênica que irá desembocar no mito da famigerada democracia racial. Com este capítulo inicial, o espírito se prepara para o seguinte, onde se desencadeiam as "memórias periféricas", tocando a vida cotidiana, envolvendo corpos em movimento, narradores pró- 
ximos, memória atenta que se expressa na "oralidade aflorada no entretecer de vozes na transversal do discurso que se quer único, nos arredores/artérias buliçosas da cidade; a oralidade na manifestação dos simples, na ópera cotidiana dos artesãos da vida". É a captação dessa energia que se acentua a partir da segunda parte da obra, onde aparece o "tempo dos quintais", desnudando alegrias e feridas não cicatrizadas na memória, com as suas compensações e alianças para sobreviver e burlar a ordem instituída. Os relatos extravasam de uma "conversa" informal, abrindo uma interlocução espontânea, partilhando uma confiança mútua, como se entrevistadora e entrevistadas compusessem uma família ampliada. Mas a subjetividade não sufoca o olhar crítico e a competência intelectual que se formula com a leveza de um discurso sensível à palavra do outro, captada no instante em que se vive, sem a pretensão de estar fazendo história para a posteridade. Surgem os lapsos, as contradições, detalhes aparentemente insignificantes, registrados por depoentes, muitos dos quais participaram de histórias que se tornaram lendas, como é o caso do Almirante Negro. O destaque fica por conta das grandes mães negras, a exemplo da Vó Alzira Braga da Silva, como é carinhosamente nomeada, com mais de cem anos na época da entrevista, hoje falecida, nascida no Engenho de Dentro e morando em Osvaldo Cruz, na mesma casa, há 70 anos. É ela o tronco secular que suporta multiplicados ramos, em torno do qual gravitam tantas histórias de resistência, permeadas pela labuta diária, onde a poesia também torna-se possível, como se lê no relato de uma das narradoras: "Eu trabalhava a semana toda na lavoura, meu pai e meus irmãos na casa de farinha. Quando chegava sábado, botava um vestido bonito, sentava na pedra em noite de lua..."

Embora a figura centenária da Vó Alzira centralize a atenção da entrevistadora, outras vozes ecoam no discurso, nem sempre afirmativas, muitas vezes tentando camuflar as marcas da miséria e da violência que se abatem sobre a população negra, esforçando-se para esquecer uma origem que torna-se estigma da maldição. Se nem tudo são histórias de resistência nas narrativas, ela será, entretanto, fundamental para compreender um sistema de alianças e as várias estratégias do mais oprimido para sobreviver ou afirmar-se, sobretudo entre a população dos afro-descendentes, como se pode depreender das narrativas, especialmente enunciadas por mulheres, detentoras de poderes nem sempre visíveis, porém, capazes de reatar as pontas da vida, lutando no meio familiar contra as forças de dispersão, geralmente abandonadas por homens que as 
deixam sem recursos financeiros e com numerosos filhos e agregados para sustentar. O importante é espicaçar a memória para que os nós se desatem, para que a palavra se solte, mostrando um feitio de viver, como uma forma particular de saltar obstáculos, de festejar e de rir no meio das desgraças, ironicamente. É dessa forma que a memória instigada vai preenchendo lacunas, revelando a energia transformadora, o sofrimento contido, a fé e a utopia, o congraçamento, a vaidade e o desejo de querer bem-viver das mulheres que prosseguem "burlando a dor, persistindo em ancorar suas memórias em momentos afirmativos para poderem conduzir com mais leveza seus destinos." São elas, afinal, as "obstinadas presenças, buliçosa mania de querer bem-viver. Comichões de vida como expressão de quem vislumbra a possibilidade de orientar e planejar sua vida e, além disso, pensando em Vó Alzira, demarcar um espaço de pertencimento e nele plantar-se para compor uma paisagem. Sua paisagem."

Em meio aos relatos, fatos históricos conhecidos podem ser identificados através de um novo olhar e de uma consciência que vai se descobrindo como parte de uma história. O Rio de Janeiro do início do século XX desponta com os seus antigos blocos de carnaval, as festas religiosas, Revolta da Vacina, o episódio da gripe Espanhola, em 1917, a figura lendária do Almirante Negro, na Revolta da Chibata, enfim, são muitos os relatos que nem sempre coincidem com as versões oficiais, adquirindo cores e nuances de um cotidiano preservado pela memória, tornando o passado mais próximo, como se fizesse parte do presente. Assim, numa passagem referente ao Almirante Negro a autora observa: "João Cândido liderou uma rebelião, este fato é sabido; mas desconhecíamos, por exemplo, seu hábito de usar um lenço vermelho no pescoço e que este lenço serviu-lhe como bandeira da rebelião. Assim como é interessante também tomarmos conhecimentos dos diálogos travados entre a oficialidade da Marinha Brasileira e os marinheiros rebelados, diálogos retomados em sua espontaneidade cercados de um tom que nos aproxima do desenrolar da ação." Mais adiante, ainda sobre este herói cultuado pelos movimentos negros, menciona outro "detalhe instigante", apreendido em entrevista com uma filha de João Cândido: "Note-se que nosso Almirante Negro, ao contrário do que é de domínio público, jamais fora chicoteado, gozando até de boa reputação e de alguns privilégios perante a oficialidade:"..usava bigode e bigode só quem usava eram os oficiais e ele apenas recebia repreensão branda." 
A publicação de Feitio de Viver pode ser providencial num momento em que ganham força algumas iniciativas para se ensinar a História e a Cultura africanas e dos afro-descendentes nas escolas, com o amparo de uma lei que representa, sem dúvida, uma vitória dos movimentos afirmativos dos negros, no Brasil.Mas, é bom lembrar que Feitio de viver não é um livro de circunstância, mas o produto de uma longa maturação intelectual e de quatro anos de entrevistas que representaram um convívio muito estreito da autora com seus entrevistados, munida de seriedade intelectual, de uma metodologia de trabalho e de muita sensibilidade para promover um diálogo promissor da instituição acadêmica com os meios periféricos da sociedade, captando neles uma história social que se constitui no fluxo da oralidade. É o que se constata em Feitio de Viver, quando as mulheres negras, representadas especialmente pela Vó Alzira, tomam a palavra para contar as suas/nossas histórias. 